Research, Society and Development, v. 9, n. 11, e5659119451, 2020

(CC BY 4.0) | ISSN 2525-3409 | DOI: http://dx.doi.org/10.33448/rsd-v9i11.9451

\title{
Transtornos alimentares e percepção de autoimagem
}

Eating disorders and self-image perception

Trastornos de la alimentación y percepción de la propia imagen

Recebido: 20/10/2020 | Revisado: 25/10/2020 | Aceito: 21/11/2020 | Publicado: 26/11/2020

Andressa Rodrigues Nascimento

ORCID: https://orcid.org/0000-0002-6831-8117

Centro Universitário Santo Agostinho, Brasil

E-mail: andressarodgs4@gmail.com

Keila Cristiane Batista Bezerra

ORCID: https://orcid.org/0000-0002-0425-3596

Centro Universitário Santo Agostinho, Brasil

E-mail: keilinhanut@gmail.com

\section{Resumo}

O presente estudo tem como temática o vínculo existente entre a percepção da autoimagem com os transtornos alimentares. Nesse sentido, o objetivo foi demonstrar através de artigos ligados ao tema como efetivamente os distúrbios alimentares refletem na vida das pessoas através da percepção, bem como verificar que há influências significativas no cotidiano desses indivíduos e na forma que os mesmos se apresentam e reconhecem a sua realidade. A metodologia utilizada foi o método de revisão integrativa, com pesquisas realizadas entre o período de fevereiro a abril de 2020, que objetivou encontrar trabalhos sobre o tema, filtrando as pesquisas que seriam relevantes, excluindo as que não fossem necessárias e alinhando aquelas que seriam usados no estudo. No decorrer da presente pesquisa, foi possível verificar que em muitos casos a percepção da autoimagem pode ocasionar danos à saúde e consequentemente problemas sérios, tais como: transtornos ligados à bulimia, anorexia e compulsão alimentar. Os resultados dos dados coletados indicaram que a percepção da autoimagem associada com fatores externos influencia consideravelmente na ocorrência de transtornos alimentares, afetando principalmente mulheres, adolescentes, jovens e adultos. Ademais, constatou-se que os transtornos alimentares relacionados com a percepção da autoimagem são distúrbios psíquicos. Dessa forma, concluiu-se que a avaliação nutricional de cada indivíduo é de suma importância e o primeiro passo para demonstrar para o mesmo que a imagem construída por ele nem sempre reflete a realidade saudável e ideal. 
Palavras-chave: Transtornos da alimentação; Imagem corporal; Saúde.

\begin{abstract}
The present study has as its theme the link between the perception of self-image and eating disorders. In this sense, the objective was to demonstrate through articles related to the theme how effectively eating disorders reflect on people's lives through perception, as well as verifying that there are significant influences on the daily lives of these individuals and the way they present themselves and recognize their reality. The methodology used was the integrative review method, with surveys carried out between February and April 2020, which aimed to find works on the topic, filtering the research that would be relevant, excluding those that were not necessary and aligning those that would be used in the study. In the course of this research, it was possible to verify that in many cases the perception of self-image can cause damage to health and consequently serious problems, such as: disorders related to bulimia, anorexia and binge eating. The results of the collected data indicated that the perception of self-image associated with external factors considerably influences the occurrence of eating disorders, affecting mainly women, adolescents, young people and adults. In addition, it was found that eating disorders related to the perception of self-image are psychic disorders. Thus, it was concluded that the nutritional assessment of each individual is of paramount importance and the first step to demonstrate for the same that the image built by him does not always reflect the healthy and ideal reality.
\end{abstract}

Keywords: Eating disorders; Body image; Cheers.

\title{
Resumen
}

El presente estudio tiene como tema el vínculo entre la percepción de la autoimagen y los trastornos alimentarios. En este sentido, el objetivo fue demostrar a través de artículos relacionados con la temática cómo los trastornos alimentarios se reflejan de manera efectiva en la vida de las personas a través de la percepción, así como verificar que existen influencias significativas en la vida cotidiana de estos individuos y en la forma en que se presentan y reconocen su realidad. La metodología utilizada fue el método de revisión integradora, con encuestas realizadas entre febrero y abril de 2020, que pretendían encontrar trabajos sobre el tema, filtrando las investigaciones que serían relevantes, excluyendo aquellas que no fueran necesarias y alineando las que serían utilizadas. en el estudio. En el transcurso de esta investigación se pudo constatar que en muchos casos la percepción de la autoimagen puede ocasionar daños a la salud y consecuentemente problemas graves, como: trastornos 
relacionados con la bulimia, la anorexia y los atracones. Los resultados de los datos recolectados indicaron que la percepción de autoimagen asociada a factores externos influye considerablemente en la ocurrencia de los trastornos alimentarios, afectando principalmente a mujeres, adolescentes, jóvenes y adultos. Además, se encontró que los trastornos alimentarios relacionados con la percepción de la autoimagen son trastornos psíquicos. Así, se concluyó que la valoración nutricional de cada individuo es de suma importancia y el primer paso para demostrar por el mismo que la imagen construida por él no siempre refleja la realidad sana e ideal.

Palabras clave: Trastornos de alimentación; Imagen corporal; Salud.

\section{Introdução}

A percepção do belo nem sempre foi à mesma no decorrer da história, visto que suas variações se apresentam de diversas formas ao longo dos séculos. Segundo Oliveira e Hutz (2010), o que se pode correlacionar é que os padrões de beleza, sempre foram ditados pela sociedade de cada época, e que as mulheres, principalmente, buscam segui-los para assim sentirem-se mais valorizadas.

Ademais, atualmente percebe-se que as perspectivas diante do corpo ideal cada dia estão mais inseridas na vida das pessoas, principalmente porque a tecnologia permite que os indivíduos possam interagir mais e até mesmo acompanhar a vida e o cotidiano uns dos outros, com interações instantâneas que muitas vezes transmitem uma imagem de vida "perfeita" e também de "corpo perfeito".

De acordo Kakeshita \& Almeida (2006) as expectativas são criadas diante da procura pelo que é belo e socialmente aceito pela "maioria", o que pode ocasionar não somente ilusões como também danos à saúde, visto que os ambientes socioculturais, juntamente com as redes sociais podem determinar condições para se apresentarem distúrbios alimentares.

Nesse sentido, estudos relatam que os problemas relacionados à bulimia, anorexia e transtornos alimentares estão cada dia mais presente nas vidas das pessoas, causando sofrimento e podendo em alguns casos levar até a morte. Diante desses conflitos surge a necessidade de verificar como as pessoas se veem nos dias atuais e se essa realidade condiz com o seu estado atual de saúde. Diante disso, questiona-se: como a percepção da autoimagem pode influenciar diretamente na saúde das pessoas? Assim, busca-se justificar o aprofundamento do tema e o estudo dos dados atualizados, a fim de demonstrar como o mundo científico comporta-se diante desses casos no momento atual. 
Research, Society and Development, v. 9, n. 11, e5659119451, 2020

(CC BY 4.0) | ISSN 2525-3409 | DOI: http://dx.doi.org/10.33448/rsd-v9i11.9451

Nessa perspectiva, observa-se que os transtornos alimentares podem ser determinantes no que se refere à saúde de cada indivíduo, tendo em vista que a percepção da autoimagem nem sempre condiz com a realidade apresentada, considerando ainda que dificilmente o ser humano alcançará a satisfação plena com o seu próprio corpo, buscando assim, mecanismo para melhorá-lo. De acordo com esse cenário, o acompanhamento nutricional e sua verificação são de extrema importância, tendo em vista que é através do mesmo que serão avaliadas as necessidades fisiológicas de nutrientes de cada indivíduo, sendo necessário ser realizado de forma regular.

Diante disso, o presente estudo teve como objetivo elaborar uma revisão integrativa em que avalia a influência da percepção de autoimagem no surgimento de possíveis transtornos alimentares.

O objetivo geral deste estudo é analisar como a percepção da autoimagem influencia diretamente na saúde do indivíduo, podendo em alguns casos ocasionar danos a sua saúde física e mental. No tocante ao objetivo específico, pretende-se verificar como o estado nutricional e seu acompanhamento rotineiro são necessários no combate a doenças ligadas a transtornos alimentares.

\section{Metodologia}

Estudo de revisão integrativa da literatura, tendo em vista que já é um tema anteriormente analisado e subjetivado por outros pesquisadores, possibilitando, na presente oportunidade, uma nova análise científica sobre a temática, tem natureza qualitativa e exploratória, já que foram colhidos dados através de artigos atualizados sobre o tema em questão.

Os três campos temáticos de avaliação dos artigos foram: primeiramente a conceituação da autoimagem na sociedade moderna; o segundo foi avaliar os transtornos alimentares e de autoimagem e como as novas mídias inseridas influenciam na percepção. $\mathrm{O}$ terceiro campo de avaliação dos artigos focou no tratamento nutricional e de outros campos, que partiu desde averiguar a relevância da atenção primária no combate aos transtornos alimentares e a inserção de novas técnicas no campo da nutrição, chamada de nutrição comportamental.

No tocante a revisão de literatura integrativa, pesquisas foram feitas por um período entre fevereiro de 2020 até abril do mesmo ano, com intuito de levantar estudos sobre o tema, 
filtrando as pesquisas relevantes, excluindo os que fogem do assunto e por fim selecionando os que estão alinhados a pesquisa.

Quanto à revisão dos artigos, considerou-se avaliar as discussões pertinentes na busca pelos resultados esperados com o trabalho, a fim de integrar diferentes conceitos e opiniões sobre o objeto de estudo (Botelho, De Almeida Cunha \& Macedo, 2011). O acesso a esses textos se deu através de fontes como o Scielo, Google Acadêmico e PePSIC.

Cumpre mencionar que, a pesquisa parte de um panorama de estudo e muita leitura sobre o tema e consequentemente coleta de dados pertinentes à discussão, visando uma exploração coerente com a realidade na busca de resultados satisfatórios.

Foram encontrados nos canais de pesquisas citados, Scielo, Pepsic e em grande parte no Google Acadêmico um total de 5.750 artigos com a delimitação do tema entre os três eixos definidos: autoimagem, transtorno alimentar e nutrição. Ao contraste, a busca manual teve um resultado de 41 artigos. A pesquisa levou em consideração a busca por artigos entre o período de 2016-2019, com exceção de um único artigo de 2012, colocando a exclusão de artigos duplicados, não condizentes aos três eixos de busca, de outra língua e pelo ano, o número foi de 1250 artigos. Seguindo os critérios da revisão de literatura integrativa (Botelho et al., 2011), e efetivada a análise dos resumos e textos de forma integral, incluindo os critérios de exclusão de artigos que fogem aos três eixos abordados, a pesquisa selecionou um total de 13 artigos para a sua construção.

Figura 1. Fluxograma Referente ao processo de seleção de artigos.

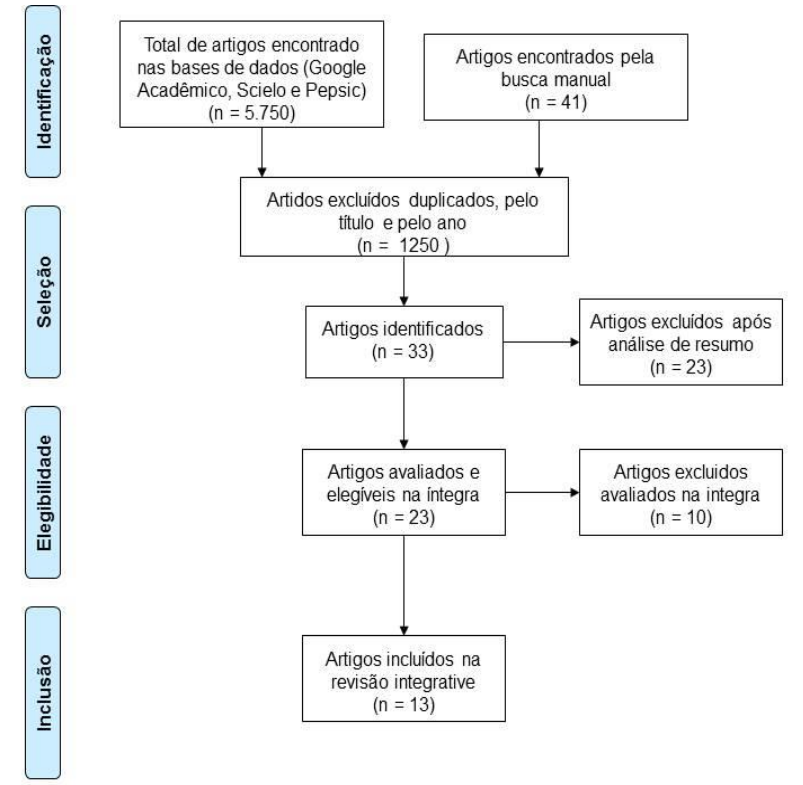

Fonte: Autores (2020). 


\section{Resultados}

A construção de avaliação dos artigos é descrita na Tabela 1, partindo da avaliação dos três eixos de pesquisa, porém, separada pelas seguintes perspectivas: o ano, os autores, o título, os objetivos, a conclusão delineamento e resultados. Para avaliar os artigos, permaneceu uma construção narrada em três demandas. A amostra integrativa da pesquisa levantou 13 artigos fundamentais para seguir a narrativa de três campos, o da autoimagem na sociedade, transtornos alimentares e de autoimagem entre diferentes grupos e o tratamento.

Tabela 1. Caracterização do estudo $(n=13)$, segundo os objetivos e delineamento das pesquisas de 2012 a 2020 .

\begin{tabular}{|c|c|c|c|c|c|}
\hline ANO & AUTORES & TÍTULO & OBJETIVOS & DELINEAMENTO & RESULTADOS \\
\hline 2018 & $\begin{array}{l}\text { De Jesus; } \\
\text { Ferreira; Da } \\
\text { Silva Lima; }\end{array}$ & $\begin{array}{c}\text { A auto } \\
\text { percepção } \\
\text { estética na } \\
\text { sociedade } \\
\text { moderna }\end{array}$ & $\begin{array}{c}\text { Identificar fatores } \\
\text { propícios à } \\
\text { dependência de } \\
\text { adultos jovens de } \\
\text { ambos os sexos na } \\
\text { prática incessante de } \\
\text { exercícios físicos em } \\
\text { prol de melhorias } \\
\text { estéticas, destacando } \\
\text { os principais } \\
\text { causadores e/ou } \\
\text { influenciadores desse } \\
\text { transtorno. }\end{array}$ & Pesquisa de revisão & $\begin{array}{l}\text { Vigorexia trata-se } \\
\text { de um transtorno } \\
\text { que pode atingir } \\
\text { homens e mulheres } \\
\text { que buscam } \\
\text { métodos e formas } \\
\text { para conseguir } \\
\text { corpos perfeitos. }\end{array}$ \\
\hline 2019 & Rodrigues; & $\begin{array}{c}\text { A influência } \\
\text { das mídias } \\
\text { sociais na } \\
\text { autoimagem } \\
\text { da mulher e } \\
\text { suas relações } \\
\text { no } \\
\text { desenvolvime } \\
\text { nto dos } \\
\text { transtornos } \\
\text { alimentares. }\end{array}$ & $\begin{array}{c}\text { Compreender a } \\
\text { influência das mídias } \\
\text { sociais na } \\
\text { autoimagem e no } \\
\text { desenvolvimento de } \\
\text { transtornos } \\
\text { alimentares em } \\
\text { mulheres. }\end{array}$ & $\begin{array}{c}\text { Abordagem } \\
\text { qualitativa, descritiva } \\
\text { e exploratória. }\end{array}$ & $\begin{array}{l}\text { O padrão de beleza } \\
\text { modifica-se } \\
\text { dependendo da } \\
\text { época e as mídias } \\
\text { sociais, apresentam } \\
\text { hoje um papel mais } \\
\text { significativo da } \\
\text { representação social } \\
\text { do que é } \\
\text { considerado belo e } \\
\text { ideal para atingir o } \\
\text { modelo de beleza } \\
\text { imposto pela } \\
\text { sociedade. }\end{array}$ \\
\hline 2020 & $\begin{array}{c}\text { Moehlecke; } \\
\text { Blume; } \\
\text { Cureau; } \\
\text { Kieling; } \\
\text { Schaan; }\end{array}$ & $\begin{array}{c}\text { Estado } \\
\text { nutricional, } \\
\text { avaliação de } \\
\text { transtornos } \\
\text { alimentares e } \\
\text { autoimagem } \\
\text { corporal em } \\
\text { universitárias } \\
\text { do Rio de } \\
\text { Janeiro. }\end{array}$ & $\begin{array}{l}\text { Avaliar a percepção } \\
\text { da autoimagem } \\
\text { corporal, } \\
\text { comportamento } \\
\text { alimentar e estado } \\
\text { nutricional de } \\
\text { estudantes de } \\
\text { Nutrição e } \\
\text { Pedagogia. }\end{array}$ & $\begin{array}{c}\text { Pesquisa } \\
\text { investigativa } \\
\text { avaliativa, } \\
\text { quantitativa e } \\
\text { descritiva. }\end{array}$ & $\begin{array}{l}\text { Entre os } 71 \text { mil } \\
\quad \text { alunos } \\
\text { entrevistados, } 45 \% \\
\text { estão insatisfeitos } \\
\text { com o seu corpo, } \\
\text { tendo o gênero } \\
\text { feminino a maior } \\
\text { frequência. Entre } \\
\text { alunos do ensino } \\
\text { médio brasileiro, } 3\end{array}$ \\
\hline
\end{tabular}




\begin{tabular}{|c|c|c|c|c|c|}
\hline & & & & & $\begin{array}{l}\text { a cada } 10 \text { possuem } \\
\text { uma disfunção no } \\
\text { que se refere a sua } \\
\text { imagem corporal. }\end{array}$ \\
\hline 2018 & Guimarães; & $\begin{array}{l}\text { Técnicas da } \\
\text { nutrição } \\
\text { comportamen } \\
\text { tal no } \\
\text { tratamento } \\
\text { dos } \\
\text { transtornos } \\
\text { alimentares. }\end{array}$ & $\begin{array}{l}\text { Abordar as técnicas } \\
\text { utilizadas na nutrição } \\
\text { comportamental e } \\
\text { quais seus benefícios } \\
\text { em indivíduos que } \\
\text { sofrem transtornos } \\
\text { alimentares. }\end{array}$ & Revisão de literatura. & $\begin{array}{c}\text { No estudo feito em } \\
\text { alunos } \\
\text { Universitários do } \\
\text { Rio de Janeiro, 17\% } \\
\text { apresentam } \\
\text { distúrbios } \\
\text { alimentares. } \\
\text { Destacando os do } \\
\text { curso de Nutrição } \\
\text { que correspondem } \\
14,6 \% \text {. }\end{array}$ \\
\hline 2019 & $\begin{array}{l}\text { Oliveira; } \\
\text { Bering; } \\
\text { Oliveira; } \\
\text { Segri; }\end{array}$ & $\begin{array}{c}\text { Comportame } \\
\text { nto alimentar } \\
\text { e imagem } \\
\text { corporal em } \\
\text { universitárias } \\
\text { do curso de } \\
\text { nutrição. }\end{array}$ & $\begin{array}{l}\text { Verificar associação } \\
\text { entre o nível de } \\
\text { satisfação corporal e } \\
\text { o risco para } \\
\text { comportamento de } \\
\text { risco para transtornos } \\
\text { alimentares (TA) em } \\
\text { universitárias. }\end{array}$ & $\begin{array}{l}\text { Abordagem } \\
\text { quantitativa, } \\
\text { transversal com } \\
\text { amostra. }\end{array}$ & $\begin{array}{c}\text { Na pesquisa com } \\
140 \text { alunos do curso } \\
\text { de Nutrição, } 83,6 \% \\
\text { que cursam até o } \\
\text { quarto semestre } \\
\text { apresentam um } \\
\text { elevado índice de } \\
\text { insatisfação com o } \\
\text { seu corpo. E do } \\
\text { quinto semestre até } \\
\text { o final do curso } \\
\text { 82,6\% apresentam } \\
\text { também esse } \\
\text { quadro. }\end{array}$ \\
\hline 2019 & Dos Santos; & $\begin{array}{l}\text { Imagem } \\
\text { corporal e } \\
\text { distúrbios } \\
\text { alimentares: } \\
\text { análise das } \\
\text { opiniões de } \\
\text { alunos do } \\
\text { ensino } \\
\text { médio. }\end{array}$ & $\begin{array}{c}\text { Estudar as } \\
\text { possibilidades de } \\
\text { manifestação de } \\
\text { distúrbios de imagem } \\
\text { corporal em alunos } \\
\text { entre } 15 \text { e } 17 \text { anos } \\
\text { que frequentam aulas } \\
\text { de Educação Física } \\
\text { na Rede Oficial de } \\
\text { Ensino Médio. }\end{array}$ & $\begin{array}{c}\text { Pesquisa descritiva } \\
\text { qualitativa. }\end{array}$ & $\begin{array}{c}21,7 \% \text { e } 26 \% \text { das } \\
\text { universitárias } \\
\text { brasileiras que } \\
\text { cursam área da } \\
\text { saúde no Brasil } \\
\text { correm sérios riscos } \\
\text { de apresentarem } \\
\text { transtornos } \\
\text { alimentares. Visto } \\
\text { que, } 49 \% \text { estão } \\
\text { insatisfeitas com } \\
\text { padrão de beleza e } \\
54 \% \text { estão } \\
\text { insatisfeitas com } \\
\text { seu corpo. }\end{array}$ \\
\hline 2018 & $\begin{array}{l}\text { Sousa; } \\
\text { Costa; }\end{array}$ & $\begin{array}{c}\text { Tendência ao } \\
\text { desenvolvime } \\
\text { nto de } \\
\text { anorexia } \\
\text { nervosa em } \\
\text { universitárias } \\
\text { do curso de } \\
\text { nutrição do } \\
\text { centro. }\end{array}$ & $\begin{array}{l}\text { Analisar a tendência } \\
\text { ao desenvolvimento } \\
\text { de anorexia nervosa } \\
\text { assim como avaliar a } \\
\text { relação entre a } \\
\text { alteração do } \\
\text { comportamento } \\
\text { alimentar. }\end{array}$ & $\begin{array}{l}\text { Estudo experimental } \\
\text { e coleta de dados. }\end{array}$ & $\begin{array}{l}\text { Os acadêmicos } \\
\text { principalmente do } \\
\text { curso de Nutrição } \\
\text { possuem forte } \\
\text { tendência em } \\
\text { desenvolver } \\
\text { principalmente } \\
\text { anorexia nervosa. }\end{array}$ \\
\hline
\end{tabular}




\begin{tabular}{|c|c|c|c|c|c|}
\hline 2016 & Texeira; & $\begin{array}{l}\text { Estado } \\
\text { nutricional de } \\
\text { adolescentes: } \\
\text { percepção da } \\
\text { autoimagem } \\
\text { e riscos de } \\
\text { transtornos } \\
\text { alimentares. }\end{array}$ & $\begin{array}{l}\text { Identificar os riscos } \\
\text { de transtornos } \\
\text { alimentares de } \\
\text { adolescentes, } \\
\text { correlacionar com } \\
\text { idade, cor, índice de } \\
\text { massa corpórea, } \\
\text { riscos } \\
\text { cardiovasculares e } \\
\text { imagem corporal } \\
\text { entre escolas públicas } \\
\text { e privadas. }\end{array}$ & $\begin{array}{c}\text { Estudo descritivo, } \\
\text { transversal e de } \\
\text { abordagem } \\
\text { quantitativa. }\end{array}$ & $\begin{array}{l}\text { Mulheres brancas, e } \\
\text { de classe social } \\
\text { econômica alta } \\
\text { apresentam de } \\
\text { maneira mais } \\
\text { acentuada, } \\
\text { transtornos } \\
\text { alimentares e falta } \\
\text { de percepção da } \\
\text { autoimagem. }\end{array}$ \\
\hline 2012 & $\begin{array}{l}\text { Prisco; } \\
\text { Araújo; } \\
\text { Almeida; } \\
\text { Santos; }\end{array}$ & $\begin{array}{l}\text { Prevalência } \\
\text { de } \\
\text { transtornos } \\
\text { alimentares } \\
\text { em } \\
\text { trabalhadores } \\
\text { urbanos de } \\
\text { município do } \\
\text { Nordeste do } \\
\text { Brasil }\end{array}$ & $\begin{array}{c}\text { Estimar a prevalência } \\
\text { de transtornos } \\
\text { alimentares em } \\
\text { trabalhadores } \\
\text { residentes em área } \\
\text { urbana de Feira de } \\
\text { Santana, Bahia. }\end{array}$ & $\begin{array}{l}\text { Pesquisa } \\
\text { epidemiológica de } \\
\text { corte transversal } \\
\text { exploratória. }\end{array}$ & $\begin{array}{l}\text { Trabalhadores do } \\
\text { Estado da Bahia } \\
\text { apresentam } 4,3 \% \\
\text { contra } 2 \text { a 3\%, no } \\
\text { que se refere a } \\
\text { distúrbios } \\
\text { alimentares. }\end{array}$ \\
\hline 2016 & Santos; & $\begin{array}{l}\text { Distorção da } \\
\text { imagem } \\
\text { corporal e } \\
\text { distúrbio } \\
\text { alimentar em } \\
\text { atletas: papel } \\
\text { de diferentes } \\
\text { programas de } \\
\text { treinamento } \\
\text { físico. }\end{array}$ & $\begin{array}{c}\text { Analisar, através de } \\
\text { uma revisão } \\
\text { sistemática, a } \\
\text { distorção da imagem } \\
\text { corporal e os } \\
\text { distúrbios alimentares } \\
\text { em atletas de } \\
\text { diferentes } \\
\text { modalidades } \\
\text { correlacionando com } \\
\text { o programa de } \\
\text { treinamento físico } \\
\text { utilizado para cada } \\
\text { modalidade. }\end{array}$ & $\begin{array}{c}\text { Revisão sistemática } \\
\text { de literatura. }\end{array}$ & $\begin{array}{c}\text { Os distúrbios } \\
\text { alimentares em } \\
\text { atletas apresentam } \\
\text { um alto índice, } \\
\text { principalmente } \\
\text { entre corredores } \\
\text { olímpicos, ginastas, } \\
\text { bailarinas } \\
\text { profissionais. }\end{array}$ \\
\hline 2019 & $\begin{array}{l}\text { Bodanese; } \\
\text { Padilha; }\end{array}$ & $\begin{array}{l}\text { Análise do } \\
\text { Conceito de } \\
\text { Autoimagem } \\
\text { de } \\
\text { Adolescentes } \\
\text { no Contexto } \\
\text { Escolar. }\end{array}$ & $\begin{array}{l}\text { Analisar os dados } \\
\text { obtidos para } \\
\text { verificação de como } \\
\text { se apresenta a } \\
\text { distorção da } \\
\text { autoimagem nesse } \\
\text { grupo de jovens. }\end{array}$ & $\begin{array}{l}\text { Revisão bibliográfica } \\
\text { e pesquisa de campo. }\end{array}$ & $\begin{array}{c}\text { As influências } \\
\text { sócias interferem } \\
\text { diretamente na } \\
\text { construção da } \\
\text { identidade de cada } \\
\text { pessoa. }\end{array}$ \\
\hline 2019 & $\begin{array}{l}\text { Faustino- } \\
\text { Silva; Jung; } \\
\text { La Porta; }\end{array}$ & $\begin{array}{l}\text { Abordagem } \\
\text { comportamen } \\
\text { tal como } \\
\text { estratégia } \\
\text { para o } \\
\text { tratamento da } \\
\text { obesidade na } \\
\text { Atenção } \\
\text { Primária à } \\
\text { Saúde. }\end{array}$ & $\begin{array}{l}\text { Elaboração de um } \\
\text { material científico } \\
\text { que promova } \\
\text { conhecimento sobre a } \\
\text { abordagem } \\
\text { comportamental } \\
\text { aplicada em nutrição } \\
\text { voltada para pessoas } \\
\text { com obesidade. }\end{array}$ & $\begin{array}{l}\text { Revisão bibliográfica } \\
\text { e de campo. }\end{array}$ & $\begin{array}{l}\text { Os profissionais de } \\
\text { Nutrição } \\
\text { juntamente com os } \\
\text { de atenção básica } \\
\text { são fundamentais } \\
\text { no combate aos } \\
\text { transtornos } \\
\text { alimentares e } \\
\text { autoimagem. }\end{array}$ \\
\hline 2017 & $\begin{array}{l}\text { Catão; } \\
\text { Tavares; }\end{array}$ & $\begin{array}{c}\text { Técnicas da } \\
\text { nutrição }\end{array}$ & $\begin{array}{l}\text { Abordar as técnicas } \\
\text { utilizadas na nutrição }\end{array}$ & Revisão de literatura. & $\begin{array}{c}\text { A nutrição } \\
\text { comportamental }\end{array}$ \\
\hline
\end{tabular}


Research, Society and Development, v. 9, n. 11, e5659119451, 2020

(CC BY 4.0) | ISSN 2525-3409 | DOI: http://dx.doi.org/10.33448/rsd-v9i11.9451

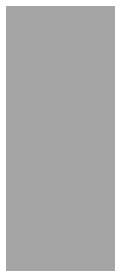

comportamen

tal no

tratamento

dos

transtornos

alimentares.

comportamental e
quais seus benefícios
em indivíduos que
sofrem transtornos
alimentares.

comportamental e

quais seus benefícios

sofrem transtornos visa uma avaliação

sobre o

comportamento humano,

psicológico, social,

cultural e

econômico.

Fonte: Dados da pesquisa (2020).

\section{Discussão}

Consoante exposto nos estudos descritos e analisados na tabela 01, a busca desmedida por um padrão físico socialmente imposto pode ocasionar transtornos alimentares, bem como foi constatado a importância do profissional da nutrição no combate aos transtornos alimentares e autoimagem.

Nesse sentido, De Jesus, Ferreira \& Da Silva Lima (2018) aduzem que o conhecimento sobre a autoimagem, a procura pela plena satisfação corporal, a busca incessante de conquistar a imagem e semelhança do outro como premissa fundamental do que é completo ideal e bonito é chamado de vigorexia. O referido transtorno baseia-se em encontrar métodos e formas do corpo perfeito, podendo causar outros transtornos alimentares e de imagem, afetando consequentemente tanto o homem quanto a mulher. Um estudo levantado pelo mesmo autor inclui dados sobre a autoimagem e indica que 10.692 jovens entre 11 e 19 anos tem incertezas sobre o seu corpo e sobre a sua autoimagem. Ressalte-se que, a adolescência é a fase mais delicada na construção de identidade de todo corpo e principalmente como o seu corpo e imagem vão se expressar no mundo, visto que neste período da vida ocorre o desenvolvimento de doenças psíquicas, distúrbios alimentares e a vigorexia.

Diante disso, Rodrigues (2019) dispõe que dependendo do grupo que o indivíduo é inserido, tempo, sociedade, consumo e comportamento coletivo, a percepção da autoimagem e como cada corpo vai se comportar e se identificar se modifica, pois existe para cada tempo um padrão de beleza a ser alcançado. Todas as nossas experiências e tudo que colhemos de informação, representação e sistemática social ideal tem um determinismo midiático de marketing como fomentação de formulações de regimento sobre os corpos. O consumo excessivo das mídias sociais corrobora entre o limiar do desejo e o corpo que é representado como ideal e belo. Ocasionando assim instrumentos de distúrbios sobre a autoimagem pessoal, que ocorrem quando o indivíduo não se vê representado por esses canais de comunicação. 
Research, Society and Development, v. 9, n. 11, e5659119451, 2020

(CC BY 4.0) | ISSN 2525-3409 | DOI: http://dx.doi.org/10.33448/rsd-v9i11.9451

De acordo com um estudo efetuado por Moehlek, Blume, Cureau, Kieling \& Schaan, (2020) em caráter nacional, para avaliar a insatisfação dos adolescentes com o seu corpo, observou-se que entre o gênero masculino a procura é representada por um corpo ideal atlético, enquanto que para o gênero feminino o modelo de corpo ideal é representado pelo manequim menor, ou seja, magro. O referido trabalho ao analisar a busca do corpo ideal constatou que existe um desconhecimento sobre o status do peso, dando uma crescente margem aos distúrbios alimentares, disfunção corporal e psíquica. Diante disso, o estudo verificou que $45 \%$ dos mais de 71 mil alunos entrevistados se mostram insatisfeitos com o seu corpo, sendo a maior incidência entre o grupo do gênero feminino, concluindo que entre os alunos do ensino médio brasileiro, 03 a cada 10 alunos apresentam uma disfunção sobre a imagem do seu corpo.

Nessa perspectiva, Guimarães (2018) através de um estudo realizado com alunos universitários no Rio de Janeiro, verificou que do percentual total dos graduandos, 17\% apresentaram signos que representam o transtorno alimentar. $\mathrm{O}$ estudo apontou uma amostra sobre os transtornos alimentares em dois grupos de graduação diferentes, o de pedagogia e nutrição, tendo o primeiro 6,2\% e o último 14,6\%. A amostragem também avaliou que 69,4\% dos estudantes universitários dos dois cursos gostariam de um corpo mais magro, principalmente as mulheres.

À vista disso, Oliveira, Bering, Oliveira \& Segri (2019) dispõem que os transtornos alimentares e a dificuldade da percepção da autoimagem são distúrbios psiquiátricos que afetam principalmente o grupo de mulheres (adolescentes, jovens e adultas). Em uma amostragem com 140 acadêmicas do curso de nutrição foi constado um elevado índice de insatisfação com o corpo na amostragem das estudantes de nutrição, com os seguintes percentuais auferidos: $83,1 \%$ de acadêmicas que cursam até o quarto semestre e $82,6 \%$ de acadêmicas que cursam do quinto semestre até o último período. A amostragem da pesquisa também alertou para um alto risco de transtornos alimentares em pessoas com sobrepeso, que passam a adotar o uso de vômitos, desenvolvendo bulimia e preocupações excessivas com a alimentação.

Diante disso, em um estudo realizado por Sousa \& Costa (2018) foi apontando o elevado número de profissionais da saúde com transtornos alimentares, cerca de $21,7 \%$ das universitárias no Brasil da área da saúde correm sérios riscos em apresentar transtornos alimentares, o que ocasiona um problema de saúde entre todas as áreas ao comparar o índice de $49 \%$ que apresentam uma insatisfação com o padrão de beleza e $54 \%$ que estão sujeitos a insatisfação com o seu corpo, conforme constatado por Dos Santos (2019). Diante disso, os 
casos de transtornos alimentares demandam uma atenção considerável, principalmente nos cursos de nutrição e das demais áreas da saúde, que possuem forte tendência a desenvolvê-los.

Nesse sentido, Teixeira (2018) afirma que os transtornos alimentares e a falta da percepção da autoimagem se acentuam principalmente no sexo feminino, de raça branca e de classe econômica alta, o que demonstra uma variante entre classes sociais, raça e determinados grupos. Ademais, existem relatos de pesquisas que na China os adolescentes têm enfrentado esses problemas com o uso de drogas dietéticas.

Conforme Prisco, Araújo, Almeida \& Santos (2012) os transtornos alimentares são patologias que alteram o comportamento alimentar e grupos como trabalhadores não estão distantes de sofrerem esses distúrbios, como observa uma pesquisa feita no estado da Bahia que constatou um percentual acima do esperado e encontrado em bibliografias, qual seja: $4,3 \%$ contra $2 \%$ a $3 \%$.

Corroborando com o exposto, Santos (2016) mostra o índice de distúrbios alimentares em atletas, incluindo os de alto rendimento e uma correlação com os diferentes grupos já apresentados também demonstram um elevado índice, principalmente entre ginastas, corredores olímpicos e bailarinas profissionais, que estão entre o grupo de maior acentuação. Dessa forma, acredita-se que a grande intensidade das atividades entre atletas, bem como o estresse psicológico, contribuem consideravelmente para os transtornes alimentares e a falta de percepção da autoimagem.

Sendo assim, Bodanese \& Padilha (2019) ressaltaram a importância da informação e de seu acesso, visto que ambos levam a acentuação de um referencial de vida, muitas vezes inalcançável, como também a prevenção de distúrbios alimentares e a falta de percepção da autoimagem. À vista disso, os autores supracitados aduzem que é importante que as pessoas entendam que somos agentes de reprodução e que sofremos constantes influências externas em diferentes contextos sociais, sobre nossos corpos, bem como relatam que a estranheza do diferente, a ansiedade, principalmente nas idades iniciais que se depara um paradoxo social entre a sua subjetividade contra a do mundo, recai integralmente sobre a construção da identidade de uma pessoa.

Desse modo, Faustino-Silva, Jung \& La Porta (2019) aduziram que o trabalho dos profissionais de nutrição em conjunto ao atendimento da atenção primária tem considerável importância no combate aos transtornos alimentares e autoimagem, visto que a realidade nutricional brasileira sai de uma perspectiva atrelada a desnutrição para o excesso de peso. Ressaltando ainda que, o ofício do nutricionista ortodoxo não considera outros fatores importantes para a realização de um atendimento eficiente sobre os problemas alimentares e 
de autoimagem. Diante disso, o serviço em conjunto com a atenção básica objetiva sair do método nutricional tradicional, que segue um cronograma pré-existente para reconhecer o contexto social, aspectos emocionais, psicológicos fisiológicos e sociais que atravessam o paciente.

Por conseguinte, Catão \& Tavares (2017) mencionam que as novas técnicas de abordagem que preconizam um trabalho do profissional da nutrição em conjunto com a assistência primária de saúde são conceituadas como nutrição comportamental. Longe de ter a prerrogativa de uma especialidade, a nutrição comportamental se destaca como sendo uma abordagem inovadora. Dito isso, a abordagem tem como finalidade realizar uma avaliação sobre o comportamento humano, psicológico, social, cultural e econômico, visto que são narrativas intrínsecas capazes de ocasionar os transtornos alimentares e de autoimagem, não se limitando apenas aos estudos dos alimentos, nutrientes e o corpo humano em si.

\section{Considerações Finais}

Nos estudos realizados foram constatados que os transtornos alimentares correlacionados com a percepção da autoimagem são considerados como distúrbios psíquicos e que as formas de percepção de autoimagem variam de acordo com a sociedade e o momento atual vivido por cada pessoa, haja vista que os padrões de beleza sofrem alterações de acordo com a época, os comportamentos e também os fatores socioeconômicos de uma determinada geração, bem como foi analisado que as mídias sociais e suas interações instantâneas podem influenciar na ocorrência de transtornos alimentares por instigarem a busca por um padrão de beleza socialmente "aceito" e considerado "belo", sugerindo que a felicidade não pode ser totalmente alcançada sem o enquadramento a padrões estéticos pré-estabelecidos, no qual os corpos magros e atléticos são os ideais e consequentemente os mais desejados.

Cumpre mencionar que, de acordo com os estudos apresentados há uma tendência evolutiva no tratamento em casos em que a percepção da autoimagem reflete diretamente nos distúrbios alimentares, trabalho esse que deve ser feito não somente pelo nutricionista, mas em conjunto com a atenção básica, considerando o contexto social daquele indivíduo, como também seus aspectos emocionais, sociais, dentre outros, tendo assim o que se conceitua nutrição comportamental.

Entretanto, face aos resultados explanados, aguarda-se que o presente estudo incite maiores interesses sobre a relevância da temática abordada, auxiliando em novos estudos, a fim de que profissionais da saúde e indivíduos que padeçam de distúrbios alimentares, bem 
Research, Society and Development, v. 9, n. 11, e5659119451, 2020

(CC BY 4.0) | ISSN 2525-3409 | DOI: http://dx.doi.org/10.33448/rsd-v9i11.9451

como a sociedade em geral, possam identificar com mais precisão os fatores que fomentam a ocorrência dos transtornos alimentares correlacionados com a percepção da autoimagem.

\section{Referências}

Bodanese, G. R., \& Padilha, M. E. R. (2019). Análise do Conceito de Autoimagem de Adolescentes no Contexto Escolar. Psicologado. (pp. 1-14). Recuperado dehttps://psicologado.com.br/atuacao/psicologia-escolar/analise-do-conceito-de-autoimagemde-adolescentes-no-contexto-escolar.

Botelho, L. L. R., De Almeida Cunha, C. C., \& Macedo, M. (2011). O método da revisão integrativa nos estudos organizacionais. Gestão e sociedade, 5(11), 121-136.

Catão, L. G., \& Tavares, R. L. (2020). Técnicas da Nutrição Comportamental no Tratamento dos Transtornos Alimentares. Revista Campo do Saber, 3(1).

De Jesus, V. M., Ferreira, J. M. A., \& da Silva Lima, W. (2018). A auto percepção estética na sociedade moderna. Anais da Jornada de Educação Física do Estado de Goiás (ISSN 2675 2050), 1(1), 135-139.

Dos Santos, C. R. (2019). Imagem corporal e distúrbios alimentares: análise das opiniões de alunos do ensino médio. Revista Multidisciplinar da Saúde, 1(1), 28-42.

Faustino-Silva, D. D., Jung, N. M., \& La Porta, L. L. (2019). Abordagem comportamental como estratégia para o tratamento da obesidade na Atenção Primária à Saúde. APS EM REVISTA, 1(3), 189-197.

Guimarães, I. C. T. (2018). Estado nutricional, avaliação de transtornos alimentares e autoimagem corporal em universitárias do rio de janeiro. RBONE-Revista Brasileira de Obesidade, Nutrição e Emagrecimento, 12(70), 196-204.

Kakeshita, I. S., \& Almeida, S. D. S. (2006). Relação entre índice de massa corporal ea percepção da auto-imagem em universitários. Revista de Saúde Pública, 40(3), 497-504. 
Moehlecke, M., Blume, C. A., Cureau, F. V., Kieling, C., \&Schaan, B. D. (2020). Autoimagem corporal, insatisfação com o peso corporal e estado nutricional de adolescentes brasileiros: um estudo nacional. Jornal de Pediatria, 96(1), 76-83.

Oliveira, L. L., \& Hutz, C. S. (2010). Transtornos alimentares: o papel dos aspectos culturais no mundo contemporâneo. Psicologia em estudo, 15(3), 575-582.

Oliveira, T. C., Bering, T., Oliveira, J. R. T., \& Segri, N. J. (2019). Comportamento alimentar e imagem corporal em universitárias do curso de nutrição. Sigmae, 8(2), 771-778.

Prisco, A. P. K., Araújo, T. M. D., Almeida, M. M. G. D., \& Santos, K. O. B. (2013). Prevalência de transtornos alimentares em trabalhadores urbanos de município do Nordeste do Brasil. Ciência \& Saúde Coletiva, 18(4), 1109-1118.

Rodrigues, D. D. S. D. S. (2019). A influência das mídias sociais na autoimagem da mulher e suas relações no desenvolvimento dos transtornos alimentares. Universidade do Extremo Sul Catarinense do Curso de Psicologia - UNESC.

Santos, D. M. D. (2016). Distorção da imagem corporal e distúrbio alimentar em atletas: papel de diferentes programas de treinamento físico (Bachelor'sthesis). Universidade Federal de Pernambuco, Centro Acadêmico De Vitória-UFPE.

Sousa, K. M. D., \& Costa, A. B. (2018). Tendência ao desenvolvimento de anorexia nervosa em universitárias do curso de nutrição do Centro Universitário de Brasília-UniCEUB. Faculdade de Ciências da Educação e Saúde do Curso de Nutrição, Centro Universitário de Brasília - UniCEUB.

Teixeira, C. S. Estado nutricional de adolescentes: percepção da autoimagem e riscos de transtornos alimentares. (2016). Faculdade de Medicina de São José do Rio Preto - FAMERP.

\section{Porcentagem de contribuição de cada autor no manuscrito}

Andressa Rodrigues Nascimento - 50\%

Keila Cristiane Batista Bezerra - 50\% 